\title{
Visual Masking: A Reliable Measure for the Assessment of Cognitive Dysfunction in the Elderly?
}

\author{
Thomas E. Schläpfer, ${ }^{1}$ Marina Groner ${ }^{2}$ Edouard Lavoyer, ${ }^{1}$ and Hans-Ulrich Fisch ${ }^{1}$ \\ 'Department of Psychiatry and ${ }^{2}$ Department of Psychology, University of Berne, Switzerland.
}

\begin{abstract}
Reliable assessment of cognitive dysfunction in the elderly is a prerequisite for the evaluation of treatment of agerelated cognitive decline. Psychophysical thresholds are known to be more reliable than psychometric tests, as assessed by stability of performance in visual masking. A backward (Till \& Franklin, 1981) and a forward masking study (Coyne, 1981) were replicated. Thereafter, the same volunteers carried out a backward and forward masking task adapted to minimize noncognitive age-related influences: target and mask duration were individually adjusted to control for reduced eye transmissiveness. Attention was assessed with the electrooculogram; a dependent variable insensitive to sporadic decreases of attention was selected. Test-retest stability in the elderly after $2-4$ weeks was $\mathbf{r}=$ .97 in backward and $\mathrm{r}=.86$ in forward masking. As Alzheimer's disease mainly affects the cortex, backward masking, which is primarily cortical, may be useful to assess aspects of cognitive dysfunction.
\end{abstract}

$\mathrm{R}_{\mathrm{E}}^{\mathrm{E}}$ ELIABLE assessment of cognitive dysfunction in the elderly population is highly important to diagnose and evaluate the effects of treatment on age-related impairment. For this purpose, psychometric tests, mostly derived from neuropsychological test batteries, are used. It is assumed that beneficial effects of treatment should be reflected in improved performance in these tests. However, neuropsychological test batteries were designed primarily for diagnostic purposes and not for repeated (pre- vs posttreatment) administration. Little information about their objectivity, reliability, and validity in old age is available (Coper, Herrmann, Hoffmeister, \& Schärer, 1986). Even in young subjects, repeated administration may lead to learning effects that are difficult to distinguish from treatment effects (Baktir, Fisch, Huguenin, \& Bircher, 1983). In addition, noncognitive influences such as shifts of attention or changes of motivation are seldom controlled. In regard to these problems with respect to assessment of changes in cognitive performance in elderly subjects, Weingartner et al. (1987) state: "Although it is impractical, the methods used in establishing psychophysical thresholds would be the ones ideally suited to evaluating mental functions in the elderly" (p. 912). However, it seems that psychophysical methods satisfying Weingartner's challenging suggestion may already be available. The testing of one of these - visual masking - is the purpose of this study.

In fact, using psychophysical methodologies such as visual masking or visible persistence (for reviews see Breitmeyer, 1984; Di Lollo, Arnett, \& Kruk, 1982), consistent age-related differences in the rate of visual information processing have been found (Coyne, 1981; Cramer, Kietzmann, \& van Laer, 1982; Di Lollo et al., 1982; Eriksen, Hamlin, \& Breitmeyer, 1970; Till \& Franklin, 1981; Walsh, Till, \& Williams, 1978). In addition, large differences in performance in visual masking tasks have also been reported between healthy elderly subjects and patients with various degrees of Alzheimer's disease (Coyne, Liss, \& Geckler,
1984; Schlotterer, Moscovitch, \& Crapper-McLachlan, 1983).

Recently, we found that assessment of visual thresholds is more sensitive than conventional psychometric tests in the measurement of sedative effects of benzodiazepines in volunteers and patients (Baktir, Fisch, Karlaganis, Minder, \& Bircher, 1987; Branch, 1987; Emre, Groner, Hofer, Groner, \& Fisch, 1989; Fisch, Groner, Groner, \& Menz, 1983). In young subjects, visual masking can be measured reliably and learning effects can be controlled (Emre et al., 1989). Shifts of attention and motivation can be rigidly assessed by the measurement of eye movements that show whether the subject has complied with the experimenter's instructions (Groner \& Groner, 1982).

The aim of the present study was to assess the potential of visual masking to monitor the effects of treatment on cognitive dysfunction of elderly subjects. Published backward and forward masking experiments were first replicated. In a second step, age effects and stability of performance in repeated measurements were assessed with the same subjects on backward and forward masking tasks modified to reduce noncognitive age-related factors that may influence performance. The following control measures were therefore taken:

(a) To diminish the variance caused by an age-related decrease of ambient illumination reaching the retina (Fozard, Wolf, Bell, McFarland, \& Podolsky, 1977), the duration of the target exposure was made highly supercritical for each subject.

(b) Since in monotonic type A masking the relative energy (according to Bloch's Law) of the target duration compared with mask duration determines the slope of the performance curve, mask duration was set to three times that of the target duration for each individual.

(c) A dependent variable was chosen that was relatively insensitive to brief decrease of attention. Thus, the criterion 
was the ratio between correct and wrong responses rather than four successive correct responses. In addition, eye movements were monitored by the electrooculogram (EOG) to assess whether subjects complied with instructions.

(d) Decrease of accommodative power was adjusted with +1 dioptre lenses.

\section{General Materials AND MethodS}

Subjects. - All subjects were naive with regard to psychophysical experiments, and in good health as documented by medical examination and history. Pupil reaction to light, and convergence, eye movements, retina and ocular media were normal. The visual acuity (after appropriate correction) was at least one minute of arc. None had taken any licit or illicit psychotropic drug at least three weeks prior to the experiment, and alcohol consumption was stated to be less than $150 \mathrm{~g} /$ week. All subjects were asked to refrain from alcohol or stimulant beverages the evening before each experiment. The young volunteers were students at the medical school; all elderly subjects resided in the community. The older subjects were socially and intellectually active although they felt some age-related decrease in cognitive performance and expressed their interest in pharmacological or nonpharmacological therapy for prevention of intellectual decline. All subjects tolerated the experimental procedure without difficulty.

Apparatus and stimuli. - Stimuli were displayed in a three-field tachistoscope (Gerbrands model T-38-1). The distance between the observer's eye and the target was 80 $\mathrm{cm}$. The timer (Gerbrands model 03C 6) was modified so that the fixation cross was illuminated except when the target and/or the mask were displayed. The luminance in the three channels of the tachistoscope was set to $6.3 \mathrm{~cd} / \mathrm{m}^{2}$ measured at the viewing port, and ambient room luminance was in the same range (measured with a Tektronix J16 photometer).

General procedure. - Before each experiment, subjects received detailed instructions followed by several practice trials. Each trial was initiated with a verbal signal from the experimenter to look at the fixation point. Two seconds later, the sequence of stimuli was displayed and the response recorded. No feedback was given and response was forced. The interval between successive trials was $5 \mathrm{sec}$. For recording the electrooculogram (EOG), $\mathrm{AC}$ amplification was sufficient to indicate changes of eye position. Horizontal eye movements of less than $1^{\circ}$ of arc amplitude could be detected. The trial was only accepted if: (a) the subject performed an eye movement after the experimenter's signal, indicating attention to the fixation cross, and (b) no eye movements occurred before the mask was fully displayed.

\section{BACKWARD MASKING EXPERIMENTS}

Subjects. - Eight subjects were young (mean age $22.6 \pm$ $S D 2.4$ years, range $20-27$ years, 2 males and 6 females) and eight were elderly $(73.1 \pm S D 5.4$ years, range $66-80$ years, 2 females, 6 males).
Experiment 1: Partial Replication of Till and Franklin (1981), Experiments $I$ and 2.

Materials and methods. - Stimuli were bigrams consisting of 20 ordered combinations of the letters $\mathrm{H}, \mathrm{K}, \mathrm{N}, \mathrm{Z}$ (Letraset No 47-60-CN 60 pt. Helvetica Medium) printed on white tachistoscope cards. Each letter subtended $1.1^{\circ} \times 0.9^{\circ}$ with a stroke of $0.2^{\circ}$. The distance between two letters was $1.1^{\circ}$. The structure mask subtended $4^{\circ} \times 1.2^{\circ}$, and consisted of letter fragments with the same stroke as the target and a length of $1^{\circ}$; it closely resembled the mask used by Turvey (1973). All stimuli were presented monoptically to the eye with better visual acuity and were viewed through an eyepiece with an aperture of $4.5 \mathrm{~mm}$ diameter.

Procedure. - Six practice trials were given with and six without a $10 \mathrm{~ms}$ mask. The critical target duration was determined for the unmasked stimulus. Initially, the target was presented for $5 \mathrm{~ms}$. After each erroneous response, the target duration was increased in $1 \mathrm{~ms}$ steps until the criterion of four successive correct target identifications was reached. Thereafter, critical target durations were similarly determined for mask durations in the following order: $5,50,15$, 100,30 , and $75 \mathrm{~ms}$. Target duration was increased in $1 \mathrm{~ms}$ steps for mask durations of 5 and $15 \mathrm{~ms}$, and in $5 \mathrm{~ms}$ steps for mask durations of $30,50,75$, and $100 \mathrm{~ms}$. The interstimulus interval between target and mask was always zero. The criterion on each occasion was four consecutive correct responses.

Data were analyzed in a split-plot ANOVA with mask duration compared within subjects.

Results. - As detected by the EOG, one young subject performed eye movements in more than two of 24 trials, and also gave extremely inconsistent results in the masking

Replication of Till and Franklin (1981)

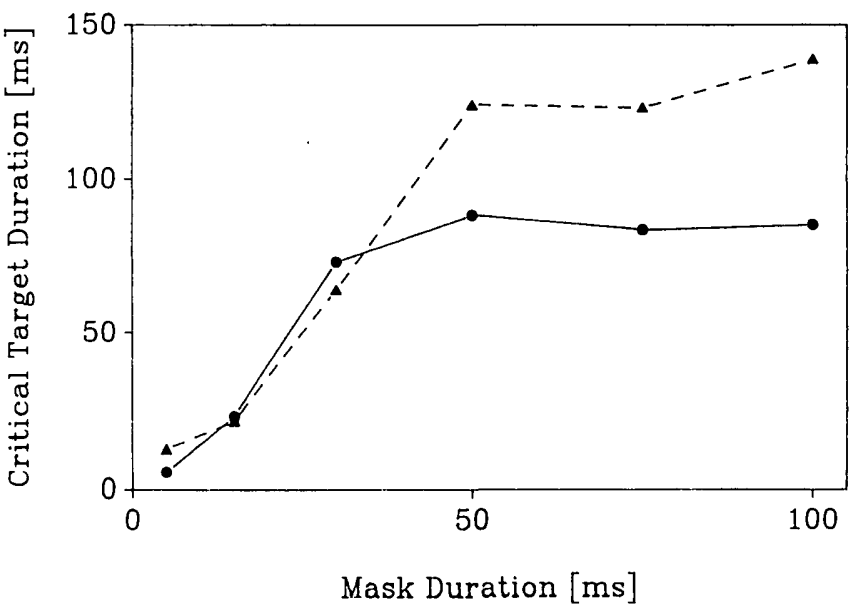

Figure I. Age differences in a backward masking task with mask duration as independent variable in 8 healthy young (mean age $22.6 \pm S D 2.3$ years) $\bullet-\bullet$ and 8 healthy elderly (mean age $73.1 \pm S D 5.1$ years) $\Delta$ volunteers. Target duration was increased until the criterion of four successive correct target determinations was reached for each mask duration. ANOVA indicated no main effect of age, but an interaction between age and mask duration $(p<.0005)$. 
experiment. She was therefore replaced. The minimal time required to identify four consecutive unmasked targets was $5.5 \pm S D 0.75 \mathrm{~ms}$ in young and $10.9 \pm 4.8 \mathrm{~ms}$ in elderly subjects: $t(14)=-3.14, p<.004$. At mask durations $>30$ ms age-related differences in critical target duration were observed (Figure 1). The ANOVA revealed a main effect of mask duration but not of age. There was, however, a highly significant interaction of age and mask duration $F(5,70)=$ $5.1, p<.0005$.

\section{Experiment 2: Backward Masking With Stimulus Onset Asynchrony (SOA) as Independent Variable}

The first masking curve was recorded at least 2 hours after the completion of Experiment 1, and the second (for the elderly subjects only) 21-28 days later. One subject was tested 13 days after the first experiment because she would otherwise have been unavailable for several months.

Material and methods. - Targets were 24 black capital letters (Letraset No. E 8). The letters subtended a visual angle of $0.39^{\circ}$ vertically and $0.33^{\circ}$ horizontally with a stroke of $0.065^{\circ}$. The structure mask subtended $1.1^{\circ} \times 0.8^{\circ}$, and was composed of black letter fragments with the same stroke as the target; this covered approximately $50 \%$ of the surface. The mask resembled as closely as possible the one used by Breitmeyer and Ganz (1976).

Procedure. - The procedure of Emre et al. (1989) was used. Critical target duration for the perception of the unmasked letters was first determined for each subject. Criterion was $80 \%$ ( 20 out of 24 ) correct answers (Eriksen et al., 1970). The initial target duration of $10 \mathrm{~ms}$ was increased in steps of $5 \mathrm{~ms}$ until the criterion was reached. Target duration was fixed at threshold $+30 \%$. Mask duration was fixed at 3

\section{BACKWARD MASKING}

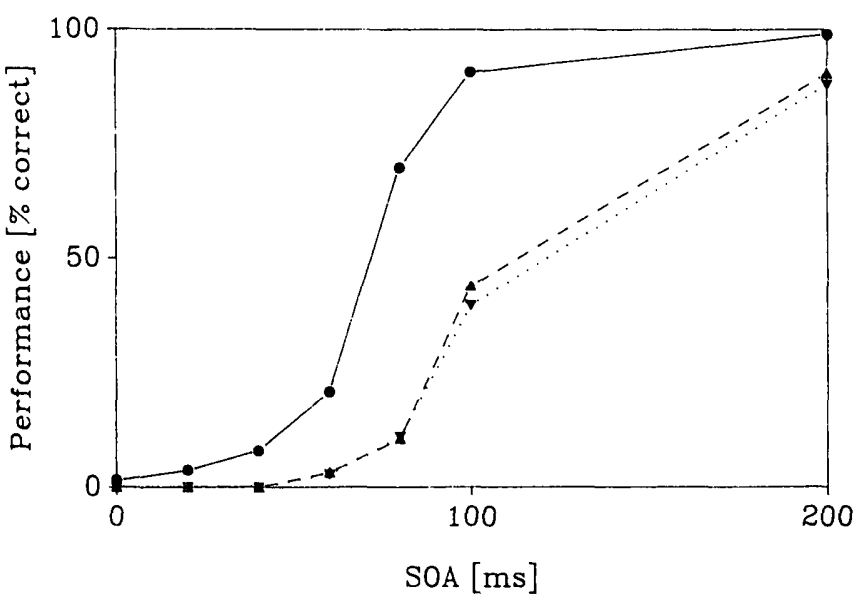

Figure 2. Age differences and stability of performance in elderly volunteers in a backward masking task with stimulus onset asynchrony as independent variable in the same 16 subjects as in Figure 1. Criterion was the percentage of correct target identifications at each SOA. ANOVA indicated a significant main effect of age $(p<.0001)$ and an interaction between age and mask duration $(p<.0001)$. $\bullet \bullet$ young volun-

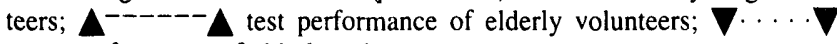
retest performance of elderly volunteers. times target duration. A session included 7 blocks, each consisting of 24 trials with the same SOA. The 7 SOA used were $0,20,40,60,80,100$, and $200 \mathrm{~ms}$, in the sequence 0 , $80,60,20,100,40$, and $200 \mathrm{~ms}$. The 24 stimulus letters were presented in random order. The arc-sin transformed data were analyzed in a split-plot ANOVA with SOA as repeated factor.

Results. - In no case had more than two trials in a single block to be repeated because of drifts or saccades in the EOG. The critical target duration was $18.8 \pm 5.2 \mathrm{~ms}$ in young and $30.6 \pm 5.0 \mathrm{~ms}$ in the elderly subjects $(t(14)=$ $-3.6, p<.002)$. The ANOVA indicated a significant main effect of age $(F(1,14)=39.0, p<.0001)$ and SOA $(F(6$, $84)=196.9, p<.001)$ as well as an interaction of Age $\times$ SOA $(F(6,84)=16.5, p<.0001)$. The younger subjects escaped masking at shorter SOAs, and the slopes of their masking curves were much steeper compared with those of the elderly volunteers (Figure 2). In the replication of the masking curve, five of the elderly subjects needed $10 \mathrm{~ms}$ longer critical target duration $(37.5 \pm 8.4 \mathrm{~ms} t(14)=$ -0.9, n.s.) than on the first occasion, whereas the masking curves were very stable over time $(F(1,7)=0.14, p=$ .72). The test-retest correlation was $r=.97, N=32$. (To avoid an artificially high test-retest correlation due to ceiling effects, only SOAs $\geqslant 60 \mathrm{~ms}$ were considered.)

\section{FORWARD MASKING EXPERIMENTS}

Subjects. - Eight subjects were young (mean age $23.1 \pm$ $S D 3.2$ years, range 16-26 years, 5 males and 3 females) and eight elderly (mean age $70.6 \pm S D 5.0$ years, range $65-80$ years, 6 males and 2 females).

\section{Experiment 3: Partial Replication of the Forward Masking Experiment of Coyne (1981)}

Material and methods. - Targets were 10 black capital letters (A, H, I, M, O, T, U, V, W, and Y). They subtended a visual angle of $0.66^{\circ} \times 0.50^{\circ}$ with a stroke of $0.065^{\circ}$. The structure mask subtended $3.6^{\circ} \times 4.0^{\circ}$ and consisted of a $50 \%$ black $/ 50 \%$ white noise display. All stimuli were presented monoptically to the eye with the better visual acuity through an eyepiece with an aperture of $4.5 \mathrm{~mm}$ diameter.

Procedure. - The critical target duration (CTD) for the unmasked target was determined by starting at a presentation time of $1 \mathrm{~ms}$ and increasing the target duration in $1 \mathrm{~ms}$ steps after each error until four consecutive letters were correctly identified. The critical interstimulus interval (ISI) necessary to escape masking was then determined by fixing the mask duration at $100 \mathrm{~ms}$ and the target stimulus at $20 \mathrm{~ms}$. The initial ISI of $5 \mathrm{~ms}$ was increased in $5 \mathrm{~ms}$ steps until two consecutive target stimuli were correctly identified. Thereafter, practice trials followed in which 20 trials each of critical ISI $-5 \mathrm{~ms}$, critical ISI, and critical ISI $+5 \mathrm{~ms}$ were presented in random order (Hertzog, Williams, \& Walsh, 1976). The critical ISI was determined for a second time after the 60 practice trials. 


\section{FORWARD MASKING}

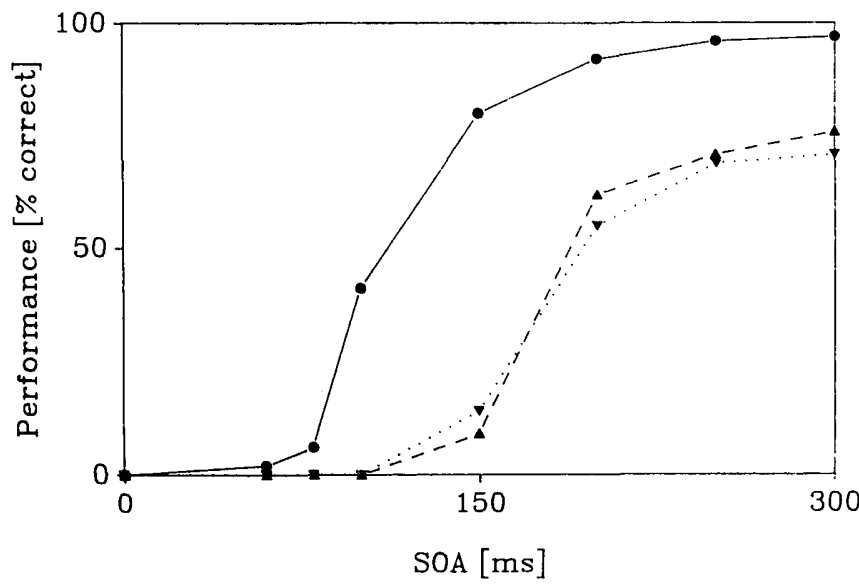

Figure 3. Age differences and stability of performance in a forward masking task with stimulus onset asynchrony as independent variable in eight healthy young (mean age 23.1 $\pm S D 3.2$ years) and eight healthy elderly subjects (mean age $70.6 \pm 5.0$ years). One elderly volunteer ( 80 years old) escaped masking only at SOAs $>300 \mathrm{~ms}$. Criterion was the percentage of correct target identification at each SOA. ANOVA indicated a significant main effect of age $(p<.0001)$ and an interaction between age and mask duration $(p<.0001)$. $\bullet$ young volunteers; $\mathbf{A}^{-----} \boldsymbol{\Delta}$ test performance of elderly volunteers; $\boldsymbol{\nabla} \cdots \cdots \boldsymbol{\nabla}$ retest performance of elderly volunteers.

Results. - In young subjects the CTD was $2 \pm 0.46 \mathrm{~ms}$ before the 60 practice trials and the critical ISI $0 \mathrm{~ms}$ with the exception of one subject in which it was $5 \mathrm{~ms}$. After practice, CTD was reduced to $2 \mathrm{~ms}$ in all subjects retested, and critical ISI was $0 \mathrm{~ms}$. In the elderly volunteers, however, CTD decreased from $5 \pm 1.6 \mathrm{~ms}$ to $4.0 \pm 1.5 \mathrm{~ms}$ (paired $t$-test $t(7)=3.1, p<.02)$ and the critical ISI from $43.5 \pm S D$ $29.8 \mathrm{~ms}$ to $25.6 \pm S D 19.1 \mathrm{~ms}$ (paired $t$-test $t(7)=4.5, p<$ $.03)$.

\section{Experiment 4}

Forward masking with SOA as independent variable. The first masking curve was recorded at least 2 hours after Experiment 3 (above), the second 25 to 62 days later.

Procedure. - Targets and mask were the same as in Experiment 2, but presented in reverse order. The sequence of the eight SOA used was $0,80,60,150,100,250,200$, and $300 \mathrm{~ms}$. Because the elderly subjects needed longer SOAs to escape masking, a cutoff criterion was introduced: after 8 consecutive errors $100 \%$ errors were assumed, in order to avoid a decrease of attention due to fatigue in the elderly subjects.

Data were analyzed in a split-plot ANOVA with mask duration compared within subjects.

Results. - In no case had more than 5 trials in a block to be repeated because of drifts or saccades in the EOG. The critical target duration was $21.9 \pm 3.2 \mathrm{~ms}$ in the young and $68.9 \pm 33.8 \mathrm{~ms}$ in the elderly subjects $(t(14)=-3.9, p<$ $.0001)$. All young subjects escaped masking at shorter SOAs compared with the elderly volunteers. One 80 -year-old sub- ject escaped masking only at SOA $>300 \mathrm{~ms}$ and reached 24 correct responses at an SOA of $900 \mathrm{~ms}$. The ANOVA indicated a significant main effect of age $(F(1,14)=30.36$, $p<.0001)$ and $\operatorname{SOA}(F(7,98)=112.0, p<.0001)$ as well as an interaction of Age $\times \operatorname{SOA}(F(7,98)=11.5, p<$ .0001 ) (Figure 3 ). In the replication of the masking curve no difference in critical target duration was observed (69.4 \pm $33.5 \mathrm{~ms}$ for test and $70.5 \pm 41.2 \mathrm{~ms}$ for retest, $t(14)=$ -.06, n.s.). The masking curve was rather stable over time $(F(1,7)=0.43, p=.53)$. To avoid an artificially high testretest correlation due to ceiling effects, only SOAs $\geqslant 150 \mathrm{~ms}$ were considered. Test-retest correlation was $r=.86, N=$ 32 . Because of the relatively low test-retest correlation, the test-retest stability of the young subjects was also assessed. It was found to be substantially higher $(r=.97, N=64)$.

\section{Discussion}

The observations confirm and extend earlier studies demonstrating large differences between age groups in visual masking performance. It was not only possible to replicate two published studies successfully but also to demonstrate consistent age effects and high test-retest stability in two masking experiments specifically designed for use in elderly subjects.

The original experiment of Till and Franklin (1981) was somewhat modified in the present replication. The elderly volunteers were considerably older, and they were equipped with $+1 \mathrm{D}$ glasses to avoid problems in accommodation. The EOG allowed control for shifts of attention; only one young subject had to be excluded because of inconsistent results due to erratic eye movements. Contrary to Till and Franklin (1981), a significant age-related difference in critical target duration was found. The curve for mean performance of subjects in both age groups was similar to that of the original experiment. The main effect of age in the experiment of Till and Franklin (1981) could not be confirmed, but a significant interaction of age and mask duration was found. Further, in distinction from the original experiment, at mask durations greater then $50 \mathrm{~ms}$ no further increase of age-related difference in performance was observed.

In the partial replication of the experiment of Coyne (1981), only two age groups were used. The mean luminance was somewhat less due to the low maximal yield in the Gerbrands tachistoscope. It was set to equal values in all three channels because the different intensities for the fixation point, target, and mask had disturbed the elderly volunteers in preliminary experiments.

The strong age effect found by Coyne (1981) was confirmed. Because the critical interstimulus interval in the young subjects was zero even before the practice phase, no learning effect in this group could be demonstrated. Both the critical target duration and the critical interstimulus interval decreased in the elderly subjects after practice.

Experiments 2 and 4 were specifically designed to minimize noncognitive influences of age. In addition to control of accommodation with $+1 \mathrm{D}$ lenses and of attention with the EOG, a dependent variable was selected which was less susceptible to the detrimental effect of small changes in attention than four successive correct responses. The per- 
centage of correct answers was used and whole masking curves were recorded using stimulus onset asynchrony as the independent variable. The most important methodological modification from earlier studies of age differences was the attempt to diminish variance caused by the possible decrease of ambient illumination reaching the retina (Fozard et al., 1977). A highly supracritical target duration was chosen for each individual subject. This compensated (according to Bloch's Law) for a possible decrease of the illumination in question.

However, not only target duration, but also mask duration, and therefore the relative energy of both, determine the slope of the masking curve. When mask energy exceeds target energy, monotonic masking curves (Type A) are observed. When mask energy is approximately equal to target energy, nonmonotonic (Type B) curves may be obtained (for a discussion see Breitmeyer, 1984). This suggests that the ratio between target and mask energy should be kept constant. Mask duration was therefore set to three times target duration for each individual. In both backward (Experiment 2) and forward (Experiment 4) masking tasks, large and consistent age effects were detected, and the testretest stability in elderly volunteers was high.

Despite the similar slopes of the masking curves, the mechanisms and anatomical substrates underlying forward and backward masking are considered to be fundamentally different. Forward monoptic masking (both target and mask are presented to the same eye) is stronger than backward monoptic masking, whereas the reverse is true for dichoptic masking (i.e., when the target is presented to one and the mask to the other eye). This suggests that in backward masking cortical information processing may be more relevant than precortical (retina and lateral geniculate nucleus; for a discussion see Breitmeyer, 1984). This distinction may be important, since morphological and biochemical changes in Alzheimer's disease are found in the cerebral cortex (Rossor, 1982), as well as in the retina and the optic nerve (Hinton, Sadun, Blanks, \& Miller, 1986).

The fact that the marked effects of age were highly reliable as demonstrated by the test-retest correlations when noncognitive variables such as attention were rigidly controlled, indicates that visual backward masking may be of use in evaluating pharmacological and nonpharmacological treatment of cognitive dysfunction in elderly subjects.

\section{ACKNOWLEDGMENTS}

This research was supported by Swiss National Science Foundation grant 3.940.0.84 and a generous grant from CIBA-GEIGY Basel.

We express our deep gratitude to Prof. C.R.B. Joyce, Department of Psychiatry, University of Berne, among others, whose contributions inproved both the message and the style.

Address correspondence and reprint requests to Dr. H.-U. Fisch, University of Berne, Department of Psychiatry, Murtenstrasse 21, CH-3010 Berne, Switzerland.

\section{REFERENCES}

Baktir, G., Fisch, H. U., Huguenin, P., \& Bircher, J. (1983). Triazolam concentration-effect relationships in healthy subjects. Clinical Pharmacology and Therapeutics, 34, 195-201.

Baktir, G., Fisch, H. U., Karlaganis, G., Minder, C. H., \& Bircher, H. (1987). Mechanisms of the excessive sedative response of cirrhotics to benzodiazepines: model experiments with triazolam. Hepatology, 7. 629-638.

Branch, R. A . (1987). Is there increased cerebral sensitivity to benzodiazepines in chronic liver disease? Hepatology, 7, 773-776.

Breitmeyer, B. G. (1984). Visual masking: An integrative approach. Oxford Psychology Series No. 4, Oxford, Clarendon Press.

Breitmeyer, B., \& Ganz, L. (1976). Implications of sustained and transient channels for theories of visual pattern masking, saccadic suppression, and information processing. Psychological Review, 83, 1-36.

Coper, H., Herrmann, W. M., Hoffmeister, F., \& Schärer, E. (1986). Impaired brain functions in old age. Report prepared by the Committee for "Geriatric diseases and asthenias," Institut für Arzneimittel des Bundesgesundheitsamtes, Berlin, FRG. (AMI-Heft 1/1986).

Coyne, A. C. (1981). Age differences and practice in forward visual masking. Journal of Gerontology, 36, 730-732.

Coyne, A. C., Liss, L., \& Geckler, C. (1984). The relationship between cognitive status and visual information processing. Journal of Gerontology, 39, 711-717.

Cramer, G., Kietzmann, M. L., \& van Laer, J. (1982). Dichoptic backward masking of letters, words and trigrams in old and young subjects. Experimental Aging Research, 8, 103-108.

Di Lollo, V., Arnett, J. L., \& Kruk, R. V. (1982). Age-related changes in rate of visual information processing. Journal of Experimental Psychology: Human Perception and Performance, 8, 225-237.

Emre, M., Groner, M., Hofer, D., Groner, R., \& Fisch, H. U. (1989). Effects of benzodiazepines on forward and backward visual masking. Clinical Vision Sciences, 4, 257-263.

Eriksen, Ch. W., Hamlin, R. M., \& Breitmeyer, R. G. (1970). Temporal factors in visual perception as related to aging. Perception \& Psychophysics, 7, 354-356.

Fisch, H. U., Groner, M., Groner, R., \& Menz, C. (1983). Influence of diazepam and methylphenidate on identification of rapidly presented letter strings: diazepam enhances visual masking. Psychopharmacology, 80, 61-66.

Fozard, J. L., Wolf, E., Bell, B., McFarland, R. A., \& Podolsky, S. (1977). Visual perception and communication. In J. W. Birren \& K. W. Schaie (Eds.), The psychology of aging. New York: Van Nostrand Reinhold.

Groner, R., \& Groner, M. (1982). Towards a hypothetico-deductive theory of cognitive activity. In R. Groner \& P. Fraisse (Eds.), Cognition and eye movements. Amsterdam: North-Holland.

Hertzog, C. K., Williams, M. V., \& Walsh, D. A. (1976). The effect of practice on age differences in central perceptual processing. Journal of Gerontology, 31, 428-433.

Hinton, D. R., Sadun, A. A., Blanks, J. C., \& Miller, C. A. (1986). Opticnerve degeneration in Alzheimer's disease. New England Journal of Medicine, 315, 485-487.

Rossor, M. N. (1982). Dementia. Lancet, ii, 1200-1204.

Schlotterer, G., Moscovitch, M., Crapper-McLachlan, D. (1983). Visual processing deficits as assessed by spatial frequency contrast sensitivity and backward masking in normal aging and Alzheimer's disease. Brain, 107, 309-325.

Till, R. E., \& Franklin, L. D. (1981). On the locus of age differences in visual information processing. Journal of Gerontology, 36, 200-210.

Walsh, D. A., Till, R. E., \& Williams, M. V. (1978). Age differences in peripheral perceptual processing: A monoptic backward masking investigation. Journal of Experimental Psychology: Human Perception and Performance, 4, 232-243.

Weingartner, H., Cohen, R., Sunderland, T., Tariot, P., Thompson, K., \& Newhouse, P. (1987). Diagnosis and assessment of cognitive dysfunctions in the elderly. In H. Y. Meltzer (Ed.), Psychopharmacology: The third generation of progress. New York: Raven Press.

Received September 15, 1988

Accepted February 14, 1990 